\title{
Introduction
}

\author{
Filipe Campante, Federico Sturzenegger \\ and Andrés Velasco
}

\section{Introduction from}

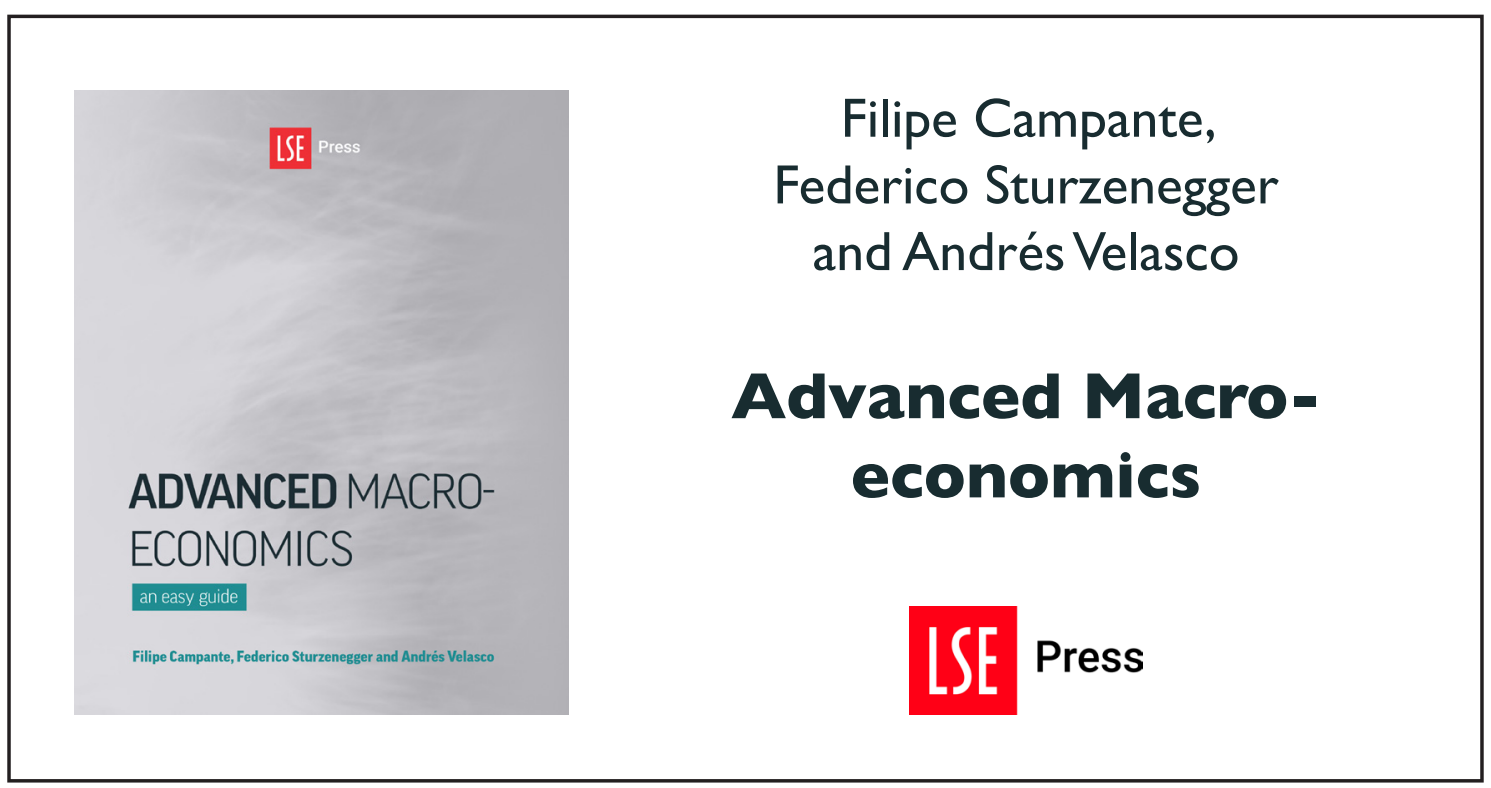

Suggested citation: Campante, Filipe; Sturzenegger, Federico; and Velasco, Andrés. (2021) 'Introduction', in Filipe Campante, Federico Sturzenegger and Andrés Velasco, Advanced Macro-Economics: An Easy Guide. London: LSE Press, 2021. https://doi. org/10.31389/lsepress.ame.a under a Creative Commons Attribution NonCommercial licence allowing users to distribute, remix, adapt, and build upon the material in any medium or format, so long as attribution is given to the creator. The license does not allow for commercial use. 


\section{Introduction}

Paul Samuelson once stated that "macroeconomics, even with all of our computers and with all of our information is not an exact science and is incapable of being an exact science". Perhaps this quote captures the view that the field of macroeconomics, the study of aggregate behaviour of the economy, is full of loose ends and inconsistent statements that make it difficult for economists to agree on anything.

While there is truth to the fact that there are plenty of disagreements among macroeconomists, we believe such a negative view is unwarranted. Since the birth of macroeconomics as a discipline in the 1930s, in spite of all the uncertainties, inconsistencies, and crises, macroeconomic performance around the world has been strong. More recently, dramatic shocks, such as the Great Financial Crisis or the Covid pandemic, have been managed - not without cost, but with effective damage control. There is much to celebrate in the field of macroeconomics.

Macroeconomics was born under the pain of both U.S. and UK's protracted recession of the 1930s. Until then, economics had dealt with markets, efficiency, trade, and incentives, but it was never thought that there was place for a large and systematic breakdown of markets. High and persistent unemployment in the U.S. required a different approach.

The main distinctive feature to be explained was the large disequilibrium in the labour market. How could it be that a massive number of people wanted to work, but could not find a job? This led to the idea of the possibility of aggregate demand shortfalls - and thus of the potential role for government to prop it up, and, in doing so, restore economic normalcy. "Have people dig a hole and fill them up if necessary" is the oft-quoted phrase by Keynes. In modern economic jargon, increase aggregate demand to move the equilibrium of the economy to a higher level of output.

Thus, an active approach to fiscal and monetary policy developed, entrusting policy makers with the role of moderating the business cycle. The relationship was enshrined in the so-called Phillips curve, a relationship that suggested a stable tradeoff between output and inflation. If so, governments simply had to choose their preferred spot on that tradeoff.

Then things changed. Higher inflation in the 60 s and 70 s, challenged the view of a stable tradeoff between output and inflation. In fact, inflation increased with no gain in output, the age of stagflation had arrived. What had changed?

The answer had to do with the role of expectations in macroeconomics. ${ }^{1}$

The stable relationship between output and inflation required static expectations. People did not expect inflation, then the government found it was in its interest to generate a bit of inflation - but

\section{How to cite this book chapter:}

Campante, F., Sturzenegger, F. and Velasco, A. 2021. Advanced Macroeconomics: An Easy Guide.

Ch. 1. 'Introduction', pp. 1-4. London: LSE Press. DOI: https://doi.org/10.31389/lsepress.ame.a License: CC-BY-NC 4.0. 
that meant people were always wrong! As they started anticipating the inflation, then its effect on employment faded away, and the effectiveness of macro policy had gone stale.

The rational expectations revolution in macroeconomics, initiated in the 1970s, imposed the constraint that a good macro model should allow agents in the model to understand it and act accordingly. This was not only a theoretical purism. It was needed to explain what was actually happening in the real world. The methodological change took hold very quickly and was embraced by the profession. As a working assumption, it is a ubiquitous feature of macroeconomics up to today.

Then an additional challenge to the world of active macroeconomic policy came about. In the early 1980s, some macroeconomists started the "real business cycles" approach: they studied the neoclassical growth model - that is, a model of optimal capital accumulation - but added to it occasional productivity shocks. The result was a simulated economy that, they argued, resembled on many dimensions the movements of the business cycle. This was a dramatic finding because it suggested that business cycles could actually be the result of optimal responses by rational economic agents, thereby eschewing the need for a stabilising policy response. What is more, active fiscal or monetary policy were not merely ineffective, as initially argued by the rational expectations view: they could actually be harmful.

This was the state of the discussion when a group of economists tackled the task of building a framework that recovered some of the features of the old Keynesian activism, but in a model with fully rational agents. They modelled price formation and introduced market structures that departed from a perfectly competitive allocation. They adhered strictly to the assumptions of rational expectations and optimisation, which had the added advantage of allowing for explicit welfare analyses. Thus, the New Keynesian approach was built. It also allowed for shocks, of course, and evolved into what is now known as dynamic stochastic general equilibrium (DSGE) models.

Macroeconomic policymaking evolved along those lines. Nowadays, DSGE models are used by any respectable central bank. Furthermore, because this type of model provides flexibility in the degree of price rigidities and market imperfections, it comprises a comprehensive framework nesting the different views about how individual markets operate, going all the way from the real business cycle approach to specifications with ample rigidities.

But the bottom line is that macroeconomics speaks with a common language. While differences in world views and policy preferences remain, having a common framework is a great achievement. It allows discussions to be framed around the parameters of a model (and whether they match the empirical evidence) - and such discussions can be more productive than those that swirl around the philosophical underpinnings of one's policy orientations.

This book, to a large extent, follows this script, covering the different views - and very importantly, the tools needed to speak the language of modern macroeconomic policymaking - in what we believe is an accessible manner. That language is that of dynamic policy problems.

We start with the Neoclassical Growth Model - a framework to think about capital accumulation through the lens of optimal consumption choices - which constitutes the basic grammar of that language of modern macroeconomics. It also allows us to spend the first half of the book studying economic growth - arguably the most important issue in macroeconomics, and one that, in recent decades, has taken up as much attention as the topic of business cycles. The study of growth will take us through the discussion of factor accumulation, productivity growth, the optimality of both the capital stock and the growth rate, and empirical work in trying to understand the proximate and fundamental causes of growth. In that process, we also develop a second canonical model in modern macroeconomics: the overlapping generations model. This lets us revisit some of the issues around capital accumulation and long-run growth, as well as study key policy issues, such as the design of pension systems. 
We then move to discuss issues of consumption and investment. These are the key macroeconomic aggregates, of course, and their study allows us to explore the power of the dynamic tools we developed in the first part of the book. They also let us introduce the role of uncertainty and expectations, as well as the connections between macroeconomics and finance.

Then, in the second half of the book, we turn to the study of business cycle fluctuations, and what policy can and should do about it. We start with the real business cycle approach, as it is based on the neoclassical growth model. Then we turn to the Keynesian approach, starting from the basic IS-LM model, familiar to anyone with an undergraduate exposure to macroeconomics, but then showing how its modern version emerged: first, with the challenge of incorporating rational expectations, and then with the fundamentals of the New Keynesian approach. Only then, we present the canonical New Keynesian framework.

Once we've covered all this material, we discuss the scope and effectiveness of fiscal policy. We also go over what optimal fiscal policy would look like, as well as some of the reasons for why in practice it departs from those prescriptions. We then move to discuss monetary policy: the relationship between money and prices, the debate on rules vs discretion, and the consensus that arose prior to the 2008 financial crisis and the Great Recession. We then cover the post-crisis development of quantitative easing, as well as the constraints imposed by the zero lower bound on nominal interest rates. We finish off by discussing some current topics that have been influencing the thinking of policymakers on the fiscal and monetary dimensions: secular stagnation, the fiscal theory of the price level, and the role of asset-price bubbles and how policy should deal with them.

As you can see from this whirlwind tour, the book covers a lot of material. Yet, it has a clear methodological structure. We develop the basic tools in the first part of the book, making clear exactly what we need at each step. All you need is a basic knowledge of calculus, differential equations, and some linear algebra - and you can consult the mathematical appendix for the basics on the tools we introduce and use in the book. Throughout, we make sure to introduce the tools not for their own sake, but in the context of studying policy-relevant issues and helping develop a framework for thinking about dynamic policy problems. We then study a range of policy issues, using those tools to bring you to the forefront of macroeconomic policy discussions. At the very end, you will also find two appendices for those interested in tackling the challenge of running and simulating their own macroeconomic models.

All in all, Samuelson was right that macroeconomics cannot be an exact science. Still, there is a heck of a lot to learn, enjoy and discover - and this, we hope, will help you become an informed participant in exciting macroeconomic policy debates. Enjoy!

\section{Note}

${ }^{1}$ Surprisingly, the answer came from the most unexpected quarter: the study of agricultural markets. As early as 1960 John Muth was studying the cobweb model, a standard model in agricultural economics. In this model the farmers look at the harvest price to decide how much they plant, but then this provides a supply the following year which is inconsistent with this price. For example a bad harvest implies a high price, a high price implies lots of planting, a big harvest next year and thus a low price! The low price motivates less planting, but then the small harvest leads to a high price the following year! In this model, farmers were systematically wrong, and kept being wrong all the time. This is nonsense, argued Muth. Not only should they learn, they know the market and they should plant the equilibrium price, namely the price that induces the amount of planting that implies that next year that will be the price. There are no cycles, no mistakes, the market equilibrium holds from day one! Transferred to macroeconomic policy, something similar was happening. 